\title{
Exploring the Significant Differences in the Importance and Frequency of Librarians' Duties among Different Library Sizes
}

\author{
Anna Maria Mouza \\ Athanasios Taousanis \\ Technological Educational Institute of Central Macedonia \\ Department of Business Administration \\ Greece
}

\begin{abstract}
This study examines the differences among the importance and frequency of librarians' duties in public libraries of different sizes in Greece, and it considers whether they have been influenced by the economic crisis. In this respect, 43 public libraries' managers evaluated 116 duties. To identify the significant differences among the libraries with respect to both their number of users and material sizes, a two-way analysis of variance was conducted. The results showed, regarding duties' importance, significant differences for the subcategory of user education according to libraries' number of users. Number of users was also related to the frequency of the subcategory collection development planning. Materialsize was significantly associated with the frequency of material ordination, and software management duties. Findings can be helpful for appropriate strategic planning, and for supporting specific actions to advance libraries' intellectual contribution.
\end{abstract}

Keywords: Public library, Duties, Importance, Frequency, Library size, Education, Economic crisis, Greece.

\section{Introduction}

Public libraries in Greece respond to the needs of the country's citizens, regardless of their demographic and socioeconomic status, intending to reach the ideal of linking knowledge with culture. To achieve this objective, most libraries have combined reading and stack rooms with other facilities, such as auxiliary areas, publicinformation centers, media labs, amphitheaters for conferences and performances, children's areas, and mobile units. They also provide creative-expression workshops and galleries for visual arts, photography presentations, and similar events.

Libraries serve as public-information centers, which are open to the public and offer free use of computer workstations, wireless connectivity, and access to various national and global collections. Additionally, in response to social needs, they provide their members with the opportunity to process the relevant e-government forms so they can easily apply for the public programs and services that meet their needs. Libraries also provide English-language learning programs for beginners. These programs have been well-attended, especially during the most recent years of the economic crisis. Further, training programs are included to assist in drafting and submitting curricula vitae, enabling users to become more competitive in the labor market. Many e-learning programs have also been implemented. All of these facilities and services have proven useful for groups identified as socioeconomically disadvantaged.

Multimedia rooms at libraries are currently open to the public. These are sound-proofed rooms that contain interactive audiovisual equipment and are especially designed for acoustic modulation. They include professional audiovisual equipment (hardware and software) such as recording studios, audio postproduction suites, listening rooms, and video editing equipment.

Additionally, libraries are well equipped with facilities for the visually impaired and people with mobility problems. These facilities provide a wide range of services, ergonomic input devices, alternative keyboards, text magnifiers, screens, talking and Braille-based books, Braille printers, and optical scanners that can convert typed text into spoken language. These services are supported by specially trained library staff, which is also responsible for implementing the relevant educational programs. 
In mobile units, contemporary equipment meets the needs of local schools that do not have libraries. In this way, they support the schools' educational work by improving the students' learning process and by providing entertainment and information, even in the most remote areas. Thus, public libraries steadily support education by implementing projects that connect school activities with those of the local society and its stakeholders. They provide high-quality services with modern technological information systems (telematics) that make it possible to connect schools with national and international information centers, thereby increasing knowledge.

\subsection{Literature Review}

The recent literature regarding public libraries is concerned mainly with two issues. First,it highlights the necessity of providing a high level of quality services; second, it provides suggestions for confronting the adverse effects of the economic crisis. Among these effects are the unfavorable impacts on Greece's public libraries due to severe funding cuts, and the consequent imposed mergers, understaffing, salary cuts, and constraints on developing library collections (Giannakopoulos et al, 2014; Vassilakaki, 2015).

Further, literature proposes developing strategic programming as a critical approach to confronting difficulties (Kostagiolas and Korkidi, 2008). Taking into account their external and internal environments, libraries should be able to identify actions necessary to continue playing an active role in their communities (Kostagiolas et al, 2009). It is vital for libraries to offer new services designed to meet the needs of users and the local community regarding unemployment, business opportunities, decision-making, new information technology, and literacy (Vassilakaki, 2015), and scholars have also indicated the imperative role of innovative information services(Kostagiolas et al, 2011; Vassilakaki and Moniarou-Papaconstantinou, 2016).

Moreover, in the current environment, researchers have highlighted the significance of human capital in achieving high performance (Asonitis and Kostagiolas, 2010). Therefore, and to mitigate the problem of underfunding following the economic crisis, new practices and reforms are recommended, many of which are already implemented in the private sector (Kondylis, 2014). For example, it is important to engage staff in decisionmaking, contributing equally, and actively helping to determine how libraries can effectively cooperate with academic institutions, the local community, ministries, and associations. Further, direct advertising, with extensive information about new developments, will advance public libraries and enhance their contribution to communities.

In this context, Mouza and Taousanis (2018) highlighted the necessity of implementing job descriptions clearly outlining public librarians' obligations; such descriptions are important for achieving competitive advantage through human resource management and for implementing the appropriate strategic planning to confront the negative consequences of the financial crisis in Greece. Additionally, significant differences regarding the duties' difficulties were analyzed and discussed. Other researchers have already presented the results of relevant investigations regarding academic libraries (Kim and Lee, 2011; Mouza and Grigoriadou, 2016).This study aims to investigate the importance and frequency of public librarians' duties, as well as their association with libraries' size, as measured by the number of users and materials, and whether the economic crisis in Greece has influenced their current status.

\section{Methodology}

To assess the importance and frequency of public library staff duties, a five-point Likert scale was used (very low to very high), ina questionnaire including 116 duties. The questionnaire was disturbed to 43 public library managers in Greece (Mouza and Taousanis, 2018). Job duties were organized in five main categories (general management, collections management, materials management, user services, and systems management), based on previous research (Yoon and Kim, 2009) and into 21 subcategories. Additionally, depending on their size, libraries were sorted to three categories: small (number of users less than 2,500; 16 libraries), medium (less than 8,000 users; 14 libraries), and large (more than 8,000 users; 13 libraries). On the basis of the number of materials, libraries ranged from less than 50,000 units (18 small libraries), 50,000-100,000units (15 medium libraries), and, for 10 large libraries, over 100,000 units. To identify significant differences among the libraries, a two-way analysis of variance (ANOVA) was conducted using SPSS 21.0.

\section{Results}

Table 1 presents the perceived importance of duties among the libraries, categorized by size according to the number of users. 
From this table, it is clear that the subcategory of user education is significant $(p=0.047)$, with an effect size of $14 \%\left(\eta^{2}=0.142\right)$, indicating a rather small effect. Applying a Bonferroni test, it was found that there is a difference between small- and medium-sized libraries $(p=0.075)$. Regarding importance, no significant differences were found for libraries sized by the number of materials.

Table 1: Differences in perceived importance of duties among libraries of different users' size

\begin{tabular}{|c|c|c|c|c|c|c|}
\hline \multirow[b]{2}{*}{ Main Category } & \multicolumn{6}{|c|}{ Users } \\
\hline & Subcategory & & & & $F$ & $p$ value \\
\hline User Services & User Education & $\begin{array}{l}\text { Small } \\
4.275\end{array}$ & $\begin{array}{l}\text { Means } \\
\text { Medium } \\
3.828\end{array}$ & $\begin{array}{l}\text { Large } \\
3.876\end{array}$ & 3.305 & $0.047 *$ \\
\hline
\end{tabular}

$(* p<0.05)$

Table 2: Differences in reported frequency of duties among libraries of different users' size

\begin{tabular}{|c|c|c|c|c|c|c|}
\hline \multirow[b]{2}{*}{ Main Category } & \multicolumn{6}{|c|}{ Users } \\
\hline & Subcategory & & Means & & $F$ & $p$ value \\
\hline Collection & Collection & Small & Medium & Large & 4489 & 0 017* \\
\hline Management & $\begin{array}{c}\text { Development } \\
\text { Planning }\end{array}$ & & & & & \\
\hline
\end{tabular}

$\left({ }^{*} p<0.05\right)$

Table 3: Differences in reported frequency of duties among libraries of different materials' size

\begin{tabular}{|c|c|c|c|c|c|c|}
\hline \multirow{3}{*}{ Main Category } & \multicolumn{6}{|c|}{ Materials } \\
\hline & Subcategory & & Means & & $F$ & $p$ value \\
\hline & & Small & Medium & Large & & \\
\hline Collection & Material & 3.222 & 2.733 & 3.320 & 3.556 & $0.038^{*}$ \\
\hline Management & Ordination & & & & & \\
\hline System & Software & 3.013 & 2.366 & 3.125 & 3.355 & $0.045^{*}$ \\
\hline Management & Management & & & & & \\
\hline
\end{tabular}

$(* \mathrm{p}<0.05)$

Table 2 depicts the significant difference $(p=0.017)$ of the subcategory collection development planning with respect to the reported frequency of duties among libraries of different size by number of users. The effect size was $18 \%\left(\eta^{2}=0.183\right)$, implying a rather small effect. Additionally, from a Bonferroni test, differences were found between medium- and large-sized libraries $(p=0.046)$ and also between medium- and small-sized libraries $(p=$ 0.034). This is explainable by the fact that the specific duties in the subcategory are observed with less frequency in medium libraries (mean=2.607).

Table 3 presents the perceived differences regarding the frequency of tasks performed among libraries with different material sizes. The results show that the subcategory of material ordination, within the main category of collections management, displays a significant difference $(p=0.038)$, with an effect size of $15 \%\left(\eta^{2}=0.151\right)$. After applying the Bonferroni test, differences were found for large- and medium-sized libraries $(p=0.078)$. Additionally, the subcategory software management appear to be significant at the $p<0.05$ level, having low effect size, at $\eta^{2}=0.144$. From the Bonferroni test, differences were found also between medium- and large-sized libraries ( $p=0.096)$, when in both above cases, it is recognized that the medium-sized libraries undertake the significant duties less frequently than the others.

\section{Discussion}

This research shows that there is a significant correlation between the subcategory user education (see Table 1) and library size. Other researchers also identify user education as being a significant asset and proposed it as a reaction against the economic crisis (Asonitis and Kostagiolas, 2010;Kostagiolas et al, 2011). 
This can be explained by taking into account the fact that public education duties constitute of one of the public libraries' main services to the community and, in particular, to small towns where citizens' training opportunities are limited. Additionally, owing to the economic crisis, libraries attract an increasing number of users, as these institutions provide various educational programs and activities where anyone can participate at no cost. Specifically, in libraries' public-information centers, users are trained on how to use software programs (for beginners, certificates are also provided) and the internet, as well as how to fill out their tax returns. Additionally, they are instructed on how to access the libraries' databases of books, journals, and other types of materials, and how to locate articles from electronic journals by searching through the vast collections offered by the HEALLink portal. Furthermore, to ensure that they meet the needs of all people, public libraries in Greece offer access to all of their services to visually impaired and physically disabled citizens. In these cases, trained library staff offer special educational programs on how to use the libraries' equipment and software. To summarize, public libraries not only offer training programs on the use of the services they provide, but they also organize and implement educational programs, which are perceived as vital because they address the particular needs of their users and local communities.

With respect to frequency, perceived differences were found among libraries of various sizes, both measured by number of users and material size. For number of users, the subcategory of collection development planning (Table 2) differs by library size; medium libraries apply these duties less frequent than large ones. Regarding material size, the subcategory of material ordination and the subcategory of software management presented the same results. This seems reasonable, since librarians who work in libraries with larger numbers of users and larger material manage the listed duties more frequently in comparison with the librarians in other libraries. Furthermore, these responsibilities are vital for the efficient operation and performance of large libraries; this provides an explanation for the result obtained.

Additionally, as shown in Tables 2 and 3, medium-sized libraries (with respect to both number of users and materials)have the lowest mean scores for all reported subcategories, even compared with small-sized ones. In our case, this is explained by the fact that six of the fourteen libraries with a medium number of users have a small number of materials; three of them indicated having especially small material, ranging from 11,000 to 22,000 units. Another six of these fourteen libraries reported having medium-sized material yet declared material sizes on the small end of the medium range, from 50,000 to 64,450.These findings indicate the importance of considering both the number of users and the collection size in describing and studying the frequency of duties performed by library staff.

\section{Conclusion}

This study investigates the significant differences in the importance of librarians' duties and their frequency among different library sizes, measured in terms of both the number of users and the material sizes of public libraries in Greece. The study also discusses whether the economic crisis influences the retrieved outcomes. Results are significant regarding the importance of duties related to user education. This is explained by the negative effect of the economic crisis, under which the citizens have expanded their interest in no-cost services for training, due to financial constraints. Additionally, results show that the frequency of librarians' duties is associated not only with library size according to number of users, but also according to material size. These findings could be valuable for library decision making regarding the strategic planning for human resource practices, as well as for enhancing librarians' efficiency and productivity under the existing financial crisis and enhancing libraries' role in their communities. A limitation of the present study is the limited number of participants; 43 library managers completed the questionnaire. Future studies must recommend specific new services regarding education and training programs to further advance the role of libraries, taking into account citizens' and local communities' needs, as well as the significant constraints of the continuing financial crisis.

\section{References}

Asonitis, S. \& Kostagiolas, P.A. (2010). An analytic hierarchy approach for intellectual capital: Evidence for the Greek central public libraries. Library Management, 31, (3), 145-161.

Giannakopoulos, G., Koulouris, A., \& Kokkinos, D. (2014). Libraries in crisis: a glimpse over Greece and Cyprus. Procedia-Social and Behavioral Sciences, 147, 411-417. 
Kim, S.Y., \& Lee, J.Y. (2011). A study on the development of Korean academic libraries' duty model based on the job analysis. Aslib Proceedings, 63, (1), 76-100.

Kondylis, D. (2014). Greek libraries' funding: a Greek tragedy with (out) euros and catharsis. The Bottom Line, 27, (2), 74-84.

Kostagiolas, P., Margiola, A. \& Avramidou, A. (2011). A library management response model against the economic crisis: The case of public libraries in Greece. Library Review, 60, (6), 486-500.

Kostagiolas, P.A., Banou, C. \& Laskari, E.M. (2009). Strategic planning and management for the public libraries: the case of Greek central public libraries. Library Management, 30, (4/5), 253-265.

Kostagiolas, P.A., \& Korkidi, M. (2008). Strategic planning for municipal libraries in Greece. New Library World, 109, (11/12), 546-558.

Mouza, A.M., \& Taousanis, A. (2018). The economic crisis and public libraries in Greece: Investigating the threats and challenges via job description. Library Management, 39, (3/4), 216-232.

Mouza, A.M., \& Grigoriadou, S.P. (2016). Job analysis of academic librarians in Greece: Investigating differences among institutions regarding obligations and responsibilities. Library Management, 37, (1/2), 29-54.

Vassilakaki, E., \& Moniarou-Papaconstantinou, V. (2016). Public Libraries and Innovation in Greece: An Option or a Necessity?, In Innovation in Libraries and Information Services, 243-255. Emerald Group Publishing Limited.

Vassilakaki, E.(2015). Greek public libraries in economic crisis: the past, the present and the future. The Bottom Line, 28, (1/2), 77-79.

Yoon, H.Y., \& Kim, S.Y. (2009). A study on the job analysis of public libraries in Korea. Aslib Proceedings, 61, (6), 504-541. 